\title{
EFFECT OF OXYGEN ION IMPLANTATION IN GALLIUM NITRIDE
}

\author{
W. Jiang*, W.J. Weber*, S. Thevuthasan*, G.J. Exarhos*, B.J. Bozlee** \\ *Pacific Northwest National Laboratory, Richland, WA 99352, weilin.jiang@pnl.gov \\ **University of Great Falls, Great Falls, MT 59405
}

Cite this article as: MRS Internet J. Nitride Semicond. Res. 4S1, G6.15 (1999)

\begin{abstract}
Epitaxial single crystal GaN films $\left(2.0 \mu \mathrm{m}\right.$ thick) were implanted $60^{\circ}$ off the $\langle 0001\rangle$ surface normal with $600 \mathrm{keV} \mathrm{O}^{+}$ions at 190 or $210 \mathrm{~K}$ over a range of ion fluences from $4.8 \times 10^{17}$ to $5.0 \times 10^{20}$ ions $/ \mathrm{m}^{2}$. The implantation damage, as determined by in-situ Rutherford Backscattering Spectrometry in a $<0001>$ channeling geometry (RBS/C), ranged from dilute defects up to the formation of a disorder saturation state that was not fully amorphous. The relative disorder on the Ga sublattice exhibited a sigmoidal dependence on ion fluence. Results show that GaN crystals are extremely resistant to the ion implantation damage as compared to other ceramic materials like SiC. An asymmetric shape in the angular scan curve around the $\langle 0001\rangle$ axis, which might be associated with the Ga lattice distortion in the crystal structure, was observed for the asirradiated material to the highest ion fluence $\left(5.0 \times 10^{20} \mathrm{O}^{+} / \mathrm{m}^{2}\right)$ at $210 \mathrm{~K}$. Comparisons of Ga disorder depth-profiles from the experiment and SRIM97 simulations suggest that the damage peaks shift to greater depths at the low irradiation temperature $(210 \mathrm{~K})$. Significant recovery of these defects was not observed in the isochronal annealing steps (20-min) up to $970 \mathrm{~K}$.
\end{abstract}

\section{INTRODUCTION}

Gallium nitride $(\mathrm{GaN})$ is being widely investigated as a material for ultraviolet emitting lasers [1] and high-power or high-temperature electronic devices [2]. A fundamental understanding of ion-implantation effects and damage recovery processes in $\mathrm{GaN}$ is important to effectively utilize ion-implantation techniques in electronic device fabrication. Much work to date has focused on n-type and p-type implantation doping [3-7] and the effects on electrical and structural properties [3-6]. Oxygen implantation is of interest as a possible alternative n-type dopant and its role as a background impurity in as-grown GaN [8]. Oxygen-implanted GaN has been shown to exhibit n-type character after $1320 \mathrm{~K}$ annealing, and no measurable change in the oxygen distribution is observed even after annealing to $1400 \mathrm{~K}$ [3]. In the present study, the effects of oxygen implantation on structure and subsequent annealing are investigated by in-situ Rutherford Backscattering Spectroscopy in a channeling geometry (RBS/C).

\section{EXPERIMENTAL PROCEDURES}

The n-type GaN single-crystal films (2.0 $\mu \mathrm{m}$ thick) used in the present investigation were obtained from Epitronics and were epitaxially grown by MOVPE on a sapphire substrate. The ion implantation and in-situ RBS/C measurements on these <0001>-oriented films were performed using a 3.4 MV tandem accelerator within the Environmental Molecular Sciences Laboratory (EMSL) at the Pacific Northwest National Laboratory. The $600 \mathrm{keV} \mathrm{O}^{+}$ions were implanted at an angle of $60^{\circ}$ relative to the surface normal in order to produce shallow damage that could be readily measured by $2 \mathrm{MeV}$ helium ion channeling. Specimens were implanted at 
low temperatures $\left(190 \mathrm{~K}\right.$ or $210 \mathrm{~K}$ ) to various fluences ranging from $4.8 \times 10^{17}-5.0 \times 10^{20} \mathrm{O}^{+} / \mathrm{m}^{2}$, equivalent to $0.026-26.7$ displacements per atom (dpa) at the depth of $\sim 0.2 \mu \mathrm{m}$ (damage peak position), where a threshold displacement energy of $25 \mathrm{eV}$ for both $\mathrm{Ga}$ and $\mathrm{N}$ sublattices have been assumed in the SRIM-97 (full cascade) simulations. The implanted areas $\left(1.2 \times 1.2 \mathrm{~mm}^{2}\right)$ had uniform ion distributions. Ion fluence integration was achieved by applying a positive voltage of $300 \mathrm{~V}$ to the target in order to prevent secondary electron emissions.

Subsequent post-irradiation and post-annealing in-situ axial-channeling analyses were performed along <0001> using $2.0 \mathrm{MeV} \mathrm{He}^{+}$beams at a scattering angle of $150^{\circ}$. During annealing, samples were heated by an electron beam from a negatively biased filament, and a steady flow of liquid nitrogen provided sample cooling. Specimen temperatures were maintained with an uncertainty of $\pm 5^{\circ} \mathrm{C}$ by adjusting both the filament current and the bias voltage (up to a maximum of $-500 \mathrm{~V}$ ) between the filament and the grounded sample. Conventional chromelalumel thermocouples were used to measure the temperatures on the sample front surfaces. Isochronal annealing at different temperature intervals for 20 minutes was used to follow the damage recovery processes over the temperature range from room temperature up to as high as $970 \mathrm{~K}$. After each isochronal annealing step, a channeling measurement along the <0001> direction was performed in-situ at a temperature below the anneal temperature to insure the annealing process was quenched. For annealing steps above $300 \mathrm{~K}$, spectra were taken after the sample cooled to room temperature. During the ion implantation and channeling measurements, the vacuum in the target chamber was typically in the range of $10^{-6} \mathrm{~Pa}$, where carbon contamination on the sample surface was not found.

\section{RESULTS AND DISCUSSION}

A sequence of in-situ $\mathrm{RBS} / \mathrm{C}$ spectra for $\mathrm{GaN} / \mathrm{Al}_{2} \mathrm{O}_{3}$ irradiated at $210 \mathrm{~K}$ to various $\mathrm{O}^{+}$ fluences is shown in Fig. 1, along with random-equivalent and virgin (unirradiated) spectra. The

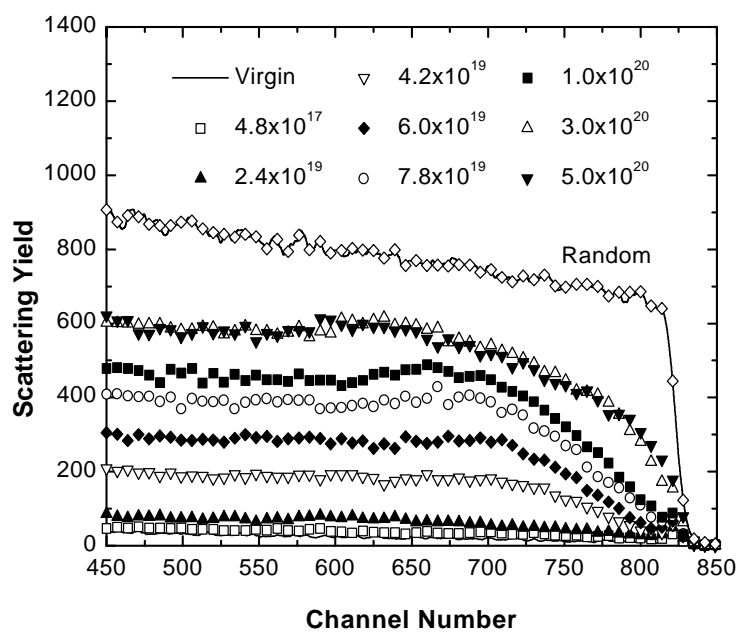

Fig. 1. A sequence of $2.0 \mathrm{MeV} \mathrm{He} \mathrm{HBS}^{+} \mathrm{C}$ spectra taken in-situ for a <0001> GaN $(2 \mu \mathrm{m}$ thick) on sapphire implanted $\left(60^{\circ}\right.$ off surface normal) in different areas with $600 \mathrm{keV} \mathrm{O}^{+}$ions at $210 \mathrm{~K}$ (dose unit: $\mathrm{O}^{+} / \mathrm{m}^{2}$ ). Also included are a random spectrum and a channeling spectrum from a virgin area.

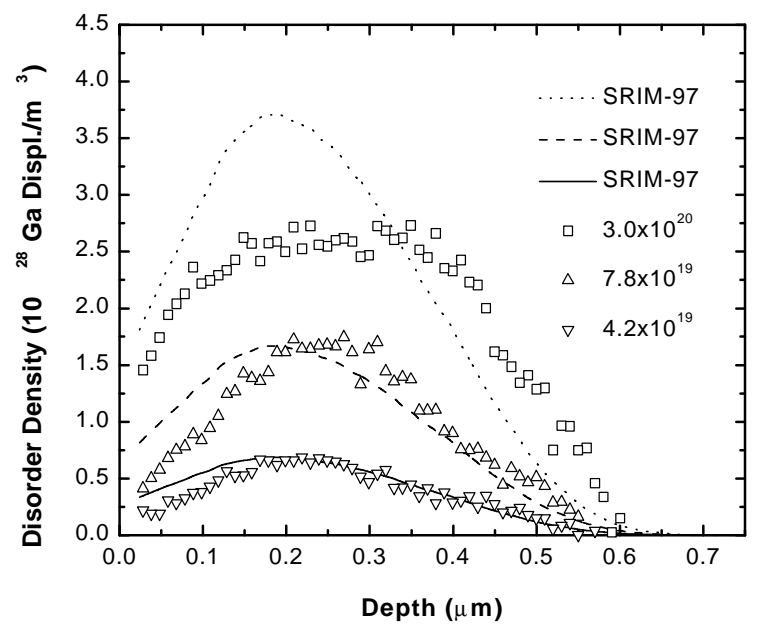

Fig. 2. Comparison of the experimentally determined disorder density profiles (from Fig. 1) for Ga sublattice with the normalized profile from SRIM-97 simulations, suggesting the damage peak shifts into the bulk at $210 \mathrm{~K}$ (dose unit: $\left.\mathrm{O}^{+} / \mathrm{m}^{2}\right)$. 
backscattering yields are monotonically increasing with ion dose up to $3.0 \times 10^{20} \mathrm{O}^{+} / \mathrm{m}^{2}$ (or 16.0 $\mathrm{dpa}$ at the damage peak). At the highest dose $\left(5.0 \times 10^{20} \mathrm{O}^{+} / \mathrm{m}^{2}\right)$, the damage accumulation appears to have saturated. The result suggests that full amorphization cannot be achieved at this temperature under $\mathrm{O}^{+}$ion irradiation. In contrast, almost two orders of magnitude lower $\mathrm{C}^{+}$[9] or $\mathrm{Si}^{+}$[10] dose (in dpa) would have been sufficient to completely amorphize $\mathrm{SiC}$ over a large depth at similar temperatures. At lower irradiation temperatures with heavier ions, complete amorphization of $\mathrm{GaN}$ does occur. For example, complete amorphization in $\mathrm{GaN}$ at $77 \mathrm{~K}$ is reported after $\mathrm{Si}^{+}$ion fluences of $2.4 \times 10^{20}$ ions $/ \mathrm{m}^{2}$ [4] and after $\mathrm{Ar}^{+}$and $\mathrm{Ca}^{+}$ion fluences of $6 \times 10^{19}$ ions $/ \mathrm{m}^{2}[11]$.

The density profiles of Ga atomic disorder for ion doses of $3.0 \times 10^{20}, 7.8 \times 10^{19}$ and $4.2 \times 10^{19}$ $\mathrm{O}^{+} / \mathrm{m}^{2}$ are extracted from the RBS/C spectra (Fig. 1) under the assumption of linear dechanneling approximation [9,12], and are shown in Fig. 2 as a function of depth. Also included in the figure are the normalized profiles from SRIM-97 simulations. Due to saturation of damage and apparent shift of the damage profile to greater depths, the measured damage profile induced by $3.0 \times 10^{20}$ $\mathrm{O}^{+} / \mathrm{m}^{2}$ irradiation does not match the simulated damage profile for this ion fluence. However, at a lower ion fluence $\left(4.2 \times 10^{19} \mathrm{O}^{+} / \mathrm{m}^{2}\right)$, the peak position of the measured disorder profile is in reasonable agreement with the simulated profile predicted by SRIM-97. As the ion fluence increases, the damage distribution appears to shift to greater depths. Since the profiles do not become wider and no evidence of defect diffusion to surface is found, the defects are expected to be immobile at this low temperature $(210 \mathrm{~K})$. The effect of damage peak shifts may be partly attributed to the interaction of Ga sublattice with oxygen dopants, which were implanted into the depth region between 0.2 and $0.5 \mu \mathrm{m}$. Further investigations are planned to depth-profile the dopant in the irradiated sample. In a related study, Zolper and co-authors [3] have reported the SIMS profiles for implanted ${ }^{18} \mathrm{O}\left(5 \times 10^{18}\right.$ ions $\left./ \mathrm{m}^{2}\right)$ in $\mathrm{GaN}$ and did not observe redistribution of the implanted species after annealing at $1400 \mathrm{~K}$ for $15 \mathrm{~s}$.

The dependence of relative $\mathrm{Ga}$ atomic disorder (at the damage peak) on the $\mathrm{O}^{+}$ion dose (in dpa) is shown in Fig. 3. Full amorphization corresponds to 1.0 on the vertical scale. The 190 and $210 \mathrm{~K}$ irradiations performed at different times show no difference within the experimental error

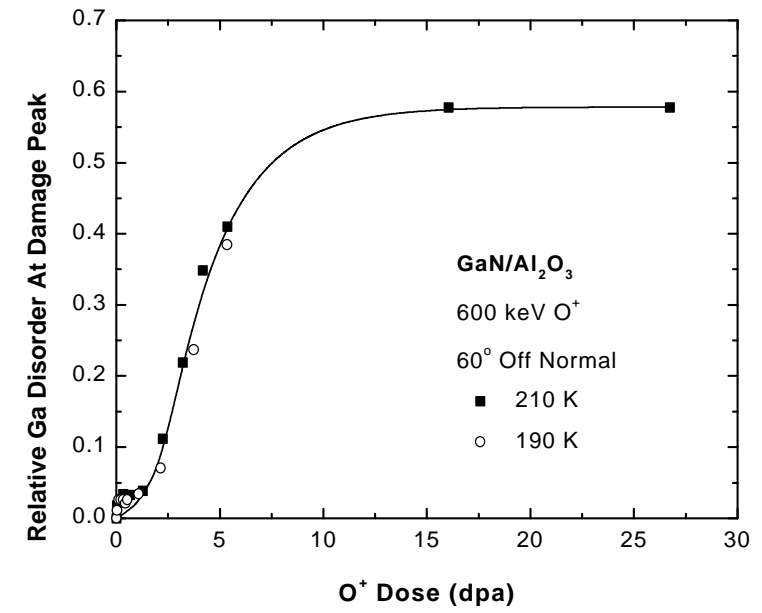

Fig. 3. Relative Ga disorder as a function of ion dose in displacements per atom (dpa) at the

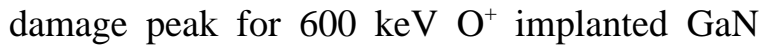
crystal on sapphire at 210 and $190 \mathrm{~K}$. The solid line is a sigmoidal fit to the data.

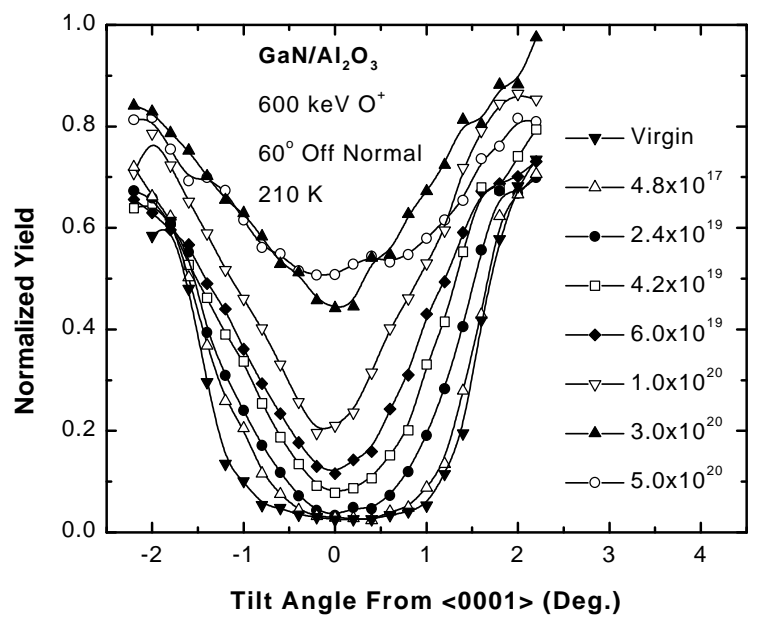

Fig. 4. Angular dependence of the normalized scattering yield of $2.0 \mathrm{MeV} \mathrm{He}^{+}$ions around $<0001>$ axis in the GaN crystalline film $(2.0 \mu \mathrm{m}$ thick) on sapphire with various ion fluences $\left(\mathrm{O}^{+} / \mathrm{m}^{2}\right)$ for the as-irradiated specimen at $210 \mathrm{~K}$. 
and give reproducible results. The maximum relative $\mathrm{Ga}$ disorder at saturation under the experimental conditions is $\sim 60 \%$ at the damage peak. The solid line in Fig. 3 is a sigmoidal fit to the data. Similar sigmoidal dependence of disorder on dose is observed in ion-implanted SiC [9,10,12-14 and refs. therein] at comparable low temperatures; however, in the case of SiC, full amorphization (100\% disorder) is achieved at significantly lower doses. Since we have not yet established how much of the disorder in Fig. 3 is due to amorphization and how much is due to defects or chemical effects (reactions with oxygen), any interpretation of the sigmoidal dependence is premature.

Figure 4 shows the evolution of the angular scan curves around the $<0001>$-axial direction with ion fluence. The random level for amorphous GaN corresponds to unity of the normalized yield. Despite the independence of minimum yields on the scanning path, the shape of the angular curves could be influenced by planar channeling [15], particularly for high-quality crystalline samples. A specific scanning path leading to a broad dip curve was selected in this study with a half-angular width of $\sim 1.7^{\circ}$ for the virgin (unimplanted) crystal, which is considered to help observe the changes in the atomic displacements more clearly. The dip curves in Fig. 4 are rather symmetric and change slowly with increasing ion dose below $1.0 \times 10^{20} \mathrm{O}^{+} / \mathrm{m}^{2}$. However, the shape becomes asymmetric for the highest dose case $\left(5.0 \times 10^{20} \mathrm{O}^{+} / \mathrm{m}^{2}\right)$, which might be associated with the disturbance of the Ga sublattice in the crystal structure. Similar dip curves have also been observed for ion-implanted $6 \mathrm{H}-\mathrm{SiC}$ materials [16].

The minimum yield $\chi_{\min }$ and the half-angular width $\Psi_{1 / 2}$ are illustrated in Fig. 5 as a function of ion fluence. A $\chi_{\min }$ of 1.0 indicates complete amorphization of the GaN material. The minimum yield, which reflects the level of the atomic disorder at surface, shows similar dependence on ion dose as in Fig. 3. However, the minimum yield has not yet saturated at $3.0 \times 10^{20} \mathrm{O}^{+} / \mathrm{m}^{2}$ due to the lower displacement dose at the surface $(\sim 7 \mathrm{dpa})$ relative to the displacement dose at the damage peak $(\sim 16 \mathrm{dpa})$ at this ion fluence. In fact, the minimum yield at the surface for this displacement dose is consistent with that at the damage peak (Fig. 3) for the same dose. This suggests that the surface is not significantly affecting the accumulation of damage at this dose level. The half-angular width $\left(\Psi_{1 / 2}\right)$ in Fig. 5 decreases slowly at lower

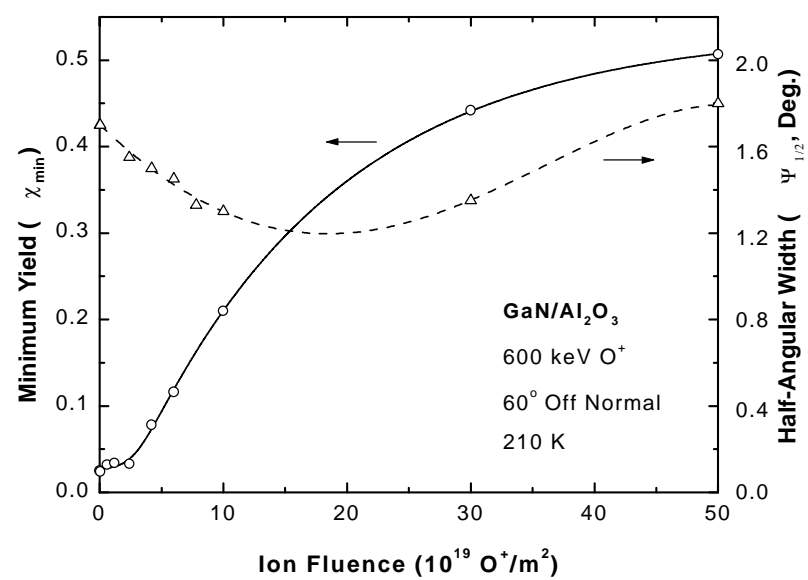

Fig. 5. Minimum yield $\left(\chi_{\min }\right)$ and half-angular width $\left(\Psi_{1 / 2}\right)$ obtained from $\mathrm{O}^{+}$ion implanted $\mathrm{GaN}$ crystal on sapphire at $210 \mathrm{~K}$ with various ion fluences. The solid (for $\chi_{\min }$ ) and dashed (for $\Psi_{1 / 2}$ ) lines are polynomial fits.

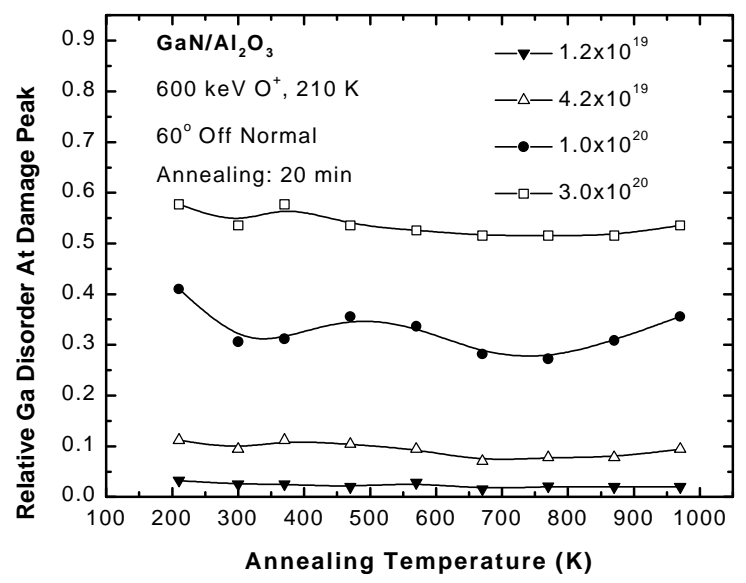

Fig. 6. Relative disorder on the Ga sublattice at damage peak as a function of annealing temperature for various ion fluences $\left(\mathrm{O}^{+} / \mathrm{m}^{2}\right)$ at $210 \mathrm{~K}$. Symbols indicate experimental data and the solid lines are polynomial fits. 
doses (below $1.0 \times 10^{20} \mathrm{O}^{+} / \mathrm{m}^{2}$, or $\sim 2.3 \mathrm{dpa}$ at surface). Although the decrease in $\Psi_{1 / 2}$ could be contributed from dopants and localized lattice distortion [17], it might also arise partly from the increase of $\mathrm{Ga}$ atomic spacing along the ion track [16]. The lattice expansion in $\mathrm{Ca}^{+}-\mathrm{and} \mathrm{Ar}^{+}-$ implanted $\mathrm{GaN}$ was observed by XRD measurements [7]. According to the polynomial curve fit (dashed line) in Fig. 5, the width tends to increase at ion fluences above $2.0 \times 10^{20} \mathrm{O}^{+} / \mathrm{m}^{2}$, which might again be related to the crystalline structural distortion discussed above.

Studies of defect recovery in the ion-implanted $\mathrm{GaN}$ materials have not been performed until recently. It has been found experimentally that defects produced by $\mathrm{Si}^{+}$implantation do not undergo significant thermal recovery at annealing temperatures up to $1070 \mathrm{~K}$ [4] or $1370 \mathrm{~K}$ [5]. However, rapid thermal annealing (RTA) studies at $1420 \mathrm{~K}$ [18] show a considerable amount of reduction in the $\mathrm{Ga}$ atomic disorder produced by irradiation at liquid nitrogen temperature with $\mathrm{Mg}^{+}$and $\mathrm{Ca}^{+}$ions. In the present study, in-situ RBS/C method is employed and the isochronal thermal annealing data (20-min) are shown in Fig. 6, where four ion fluences have been chosen as examples. The Ga atomic disorder at the damage peak for the as-implanted specimens ranged from $\sim 3 \%$ up to $\sim 58 \%$ and only some fluctuations of the $\mathrm{Ga}$ atomic disorder were observed as a result of the annealing processes. In general, no significant annealing effects occurred up to 970 $\mathrm{K}$ in any of the irradiated samples, which covered the full range of atomic disorder in this study. This is in contrast to gradual reduction of $\mathrm{Si}$ atomic disorder in $\mathrm{Si}^{+}$[10], $\mathrm{C}^{+}$[9] and $\mathrm{He}^{+}$[13] implanted $6 \mathrm{H}-\mathrm{SiC}$ in a comparable annealing temperature range. The thermal stability of the defects in $\mathrm{GaN}$ is not yet fully understood. It might be partly associated with the nature of the defects produced. Optical measurements on these samples, to be reported in a subsequent publication, indicate ingrowth of a color center near $440 \mathrm{~nm}$ produced by the ion implantation. Significant broadening in the band edge absorption line and an increase in refractive index also were determined from optical transmission and ellipsometry measurements. These effects are consistent with ion induced lattice disorder. Further work is planned to explore the nature of the defects formed and the attendant recovery mechanisms.

\section{CONCLUSIONS}

It has been shown that full amorphization of GaN may not be possible under $600 \mathrm{keV} \mathrm{O}^{+}$ irradiation at temperatures down to $\sim 200 \mathrm{~K}$. The irradiation-induced damage profile shifts to greater depths with increasing dose, and damage saturates at a value of $\sim 60 \%$. This may be due to a ballistic or chemical effect, since defects do not appear to be mobile at this temperature. The accumulation of damage on the Ga sublattice exhibits a sigmoidal dependence on dose. An observed asymmetric shape in the dip curve for an ion fluence of $5.0 \times 10^{20} \mathrm{O}^{+} / \mathrm{m}^{2}$ may be associated with a disturbance or perturbation on the Ga sublattice. No significant defect recovery is observed in $\mathrm{GaN}$ (irradiated at $210 \mathrm{~K}$ ) as a result of 20-min isochronal anneals at temperatures up $970 \mathrm{~K}$.

\section{ACKNOWLEDGMENT}

This work was supported by the Division of Materials Science, Office of Basic Energy Sciences, U.S. Department of Energy under Contract DE-AC06-76RLO 1830. Operational support for the EMSL accelerator laboratory was provided by the Office of Biological and Environmental Research, U.S. Department of Energy under Contract DE-AC06-76RLO 1830. 


\section{REFERENCES}

[1] S. Nakamura, MRS Bulletin 23 (5), 37 (1998).

[2] M.S. Shur, in Power Semiconductor Materials and Devices, edited by S.J. Pearton, R.J. Shul, E. Wolfgang, F. Ren, and S. Tenconi (Mater. Res. Soc. Proc. 483, Warrendale, PA, 1998) pp. 15-26.

[3] J.C. Zolper, R.G. Wilson, S.J. Pearton, R.A. Stall, Appl. Phys. Lett. 68, 1945 (1996).

[4] H.H. Tan, J.S. Williams, J. Zou, D.J.H. Cockayne, S.J. Pearton, R.A. Stall, Appl. Phys. Lett. 69, 2364 (1996).

[5] J.C. Zolper, M.H. Crawford, J.S. Williams, H.H. Tan, R.A. Stall, Nucl. Instrum. Methods in Phys. Res. B 127/128, 467 (1997).

[6] B. Mensching, C. Liu, B. Rauschenbach, K. Kornitzer, W. Ritter, Mater. Sci. and Eng. B 50, 105 (1997).

[7] C. Liu, B. Mensching, K. Volz, B. Rauschenbach, Appl. Phys. Lett. 71, 2313 (1997).

[8] B.-C. Chung and M. Gershenzon, J. Appl. Phys. 72, 651 (1992).

[9] W. Jiang, W.J. Weber, S. Thevuthasan, D.E. McCready, Surf. Interface Anal. (1998), in press.

[10] W. Jiang, W.J. Weber, S. Thevuthasan, D.E. McCready, Nucl. Instrum. Methods in Phys. Res. B 143, 333 (1998).

[11] C. Liu, B. Mensching, M. Zeitler, K. Volz, B. Rauschenbach, Phys. Rev. B 57, 2530 (1998).

[12] W. Jiang, W.J. Weber, S. Thevuthasan, D.E. McCready, Nucl. Instrum. Methods in Phys. Res. B, January, (1999), in press.

[13] W. Jiang, W.J. Weber, S. Thevuthasan, D.E. McCready, J. Nucl. Mater. 257, 295 (1998).

[14] W.J. Weber, L.M. Wang, N. Yu, Nucl. Instrum. Methods in Phys. Res. B 116, 322 (1996).

[15] M.L. Swanson, in Handbook of Modern Ion Beam Analysis, edited by J.R. Tesmer and M. Nastasi (Materials Research Society, Pittsburgh, PA, 1995) p. 258.

[16] W. Jiang, W.J. Weber, S. Thevuthasan, submitted to 1998 MRS Fall Meeting, Symposium N, (1998).

[17] W.K. Chu, J.W. Mayer, M.-A. Nicolet, Backscattering Spectrometry (Academic Press, 1978) pp. 269-271.

[18] C. Liu, A. Wenzel, K. Volz, B. Rauschenbach, Nucl. Instrum. Methods in Phys. Res. B, January, (1999), in press. 